NOTAS 



\title{
EL DIÁLOGO ENTRE TRIBUNALES
}

\author{
GIUSEPPE DE VERGOTTINI ${ }^{2}$ \\ Catedrático de Derecho Constitucional \\ Universidad de Bolonia
}
SUMARIO
I. Introducción.
I. La confusión entre la existencia de un espacio cultural común y el diálogo entre tribunales.
II. La interacción entre jurisdicciones en un or- denamiento internacional regional.
III. La influencia entre jurisdicciones estatales.
IV. La negativa y la imposibilidad más o menos radical de diálogo.
V. La comparación como componente del su- puesto diálogo.
VI. La confusión entre argumentos comparativos y juicios comparativos.

El diálogo entre tribunales se ha convertido, sin duda, en un lugar común en los últimos tiempos. Son escasos los trabajos en los que, abordando la jurisprudencia de tribunales internacionales y/o nacionales, no aparezcan apuntes, más o menos documentados, que incidan en la existencia de un supuesto diálogo entre los órganos jurisdiccionales. Pero en qué consiste tal diálogo es algo que no queda siempre claramente reflejado.

Fundamentalmente suele hablarse de dialogo cuando en el curso de una resolución podemos encontrar una reseña proveniente de un ordenamiento diferente; externo por

1 Traducción de F. Reviriego Picón (Profesor Titular de Derecho Constitucional. UNED).

2 Lección magistral pronunciada el 27 de abril de 2010 en la Università degli Studi Suor Orsola Benincasa, de Napoles.

N. del T.: Un estudio más profundo del autor, sobre la base de este esquema, puede verse en Oltre il dialogo tra le Corti. Giudici, diritto straniero, comparazione (Il Mulino, 2010, 224 págs).

En castellano ha sido editado bajo el título Más allá del diálogo. Comparación y relación entre jurisdicciones (Cívitas, 2011, 333 págs.) con prólogo de Javier García Roca y traducción de Pedro Tenorio Sánchez. 
tanto de aquel en el que la resolución despliega su eficacia. De tal dato se pretende obtener la confirmación de la existencia de un diálogo de jurisdicciones. Ahora bien, aun sobre la base de esa primera constatación — circulación de flujos de información sobre los pronunciamientos de los diferentes ordenes judiciales-, lo cierto es que resultaría preciso reflexionar sobre si la noción más apropiada para calificar este fenómeno es la de diálogo.

En nuestras consideraciones trataremos de abordar así si el supuesto diálogo existe o no como un fenómeno generalizado y cotejaremos las profundas diferencias entre una interacción o influencia entre jurisprudencias, lo que constituiría el diálogo en sentido propio, y una mera, aunque no por ello irrelevante, influencia de una jurisprudencia sobre otra; sin dejar de lado, por supuesto, que existen también ejemplos de rechazo de tal diálogo. También, por último, reflexionaremos sobre otro de los lugares comunes de nuestra literatura jurídica; el del recurso a la comparación por parte de los tribunales.

\section{LA CONFUSIÓN ENTRE LA EXISTENCIA DE UN ESPACIO CULTURAL COMÚN Y EL DIÁLOGO ENTRE LOS ÓRGANOS JURISDICCIONALES}

Parece una idea consolidada que viene produciéndose un intenso intercambio entre los diversos tribunales estatales y, de forma más específica, entre los tribunales estatales y los tribunales internacionales. Esto implicaría de forma inevitable la utilización del Derecho extranjero por parte de los jueces estatales y el recurso a la comparación por parte de todos aquellos. Indudablemente, en los últimos tiempos nos movemos en el marco de un espacio cultural común que conduce a la homologación de la jurisprudencia contitucional e internacional; todo ello se ha visto ayudado, en nuestro entorno más cercano, por la superación de barreras ideológicas en el curso del acercamiento de los países del Este de Europa a los Estados de consolidada democracia liberal. Si bien esto es cierto en la realidad europea y en la de los países que históricamente han estado cercanos a ella, la situación es mucho más compleja si nos salimos de ese circuito eurocéntrico. En estos casos, resulta fácil observar la fragmentación de espacios y la inexistencia de los presupuestos del diálogo.

La protección y tutela de los derechos fundamentales es el campo en el que resulta preciso hacer una salvedad. Desde un punto de vista formal parecen subsistir aquí los presupuestos de uniformidad que pueden asegurar el diálogo. Ningun Estado, por muy alejado que pueda encontrarse de la concepción de la persona y de sus derechos, típica del Estado constitucional liberal democrático, podría negar tal influencia. Cada Estado queda obligado a la observancia de la Declaración Universidad de Derechos o a las diferentes cartas vigentes a nivel regional en los diversos continentes. No obstante esta uniformidad de protección entre las constituciones y las tratados de derechos se revela aparente cuando pasamos de la declaración formal a la aplicación práctica de los principios. Al tratar de verificar la eficacia de la protección se nos ponen de relieve numerosos puntos de fricción. Resulta obvio cotejar que la hipótesis del diálogo no adopta una perspectiva universal sino que por la propia fuerza de las cosas queda circunscrita a los ordenamientos de inspiración liberal. En realidad es fácil observar que todas las veces 
que la literatura jurídica habla de diálogo cita ejemplos que provienen de tribunales pertenecientes a países que se inspiran en principios liberales y de organizaciones internacionales regionales de las que forman parte esos mismos países.

\section{LA INTERACCIÓN ENTRE JURISPRUDENCIAS EN UN ORDENAMIENTO INTERNACIONAL REGIONAL.}

Podemos hablar de la existencia de una amplia diversidad de perspectivas del diálogo en función de si éste se produce en el seno de las relaciones entre tribunales de un ordenamiento internacional regional y los tribunales estatales en ella insertos o bien se produce exclusicamente entre tribunales estatales. La superposición de normativas sobre derechos y sus medios de protección conduce a la multidimensionalidad de su tutela. Teóricamente un mismo sujeto puede gozar de diversos marcos de protección normativa traducibles en diferentes niveles de tutela. Mas en la práctica se revela necesario coordinar la forma de activar tales instrumentos y la conexión entre diferentes jurisdicciones.

En un ordenamiento internacional regional resulta inevitable la búsqueda de un equilibrio entre las competencias de intervención atribuidas a los órganos de la entidad interestatal de nueva creación y los órganos de los propios Estados que la componen. Un tribunal supranacional debe tener en cuenta a la hora de adoptar sus pronunciamientos las atribuciones residuales de lo órganos estatales, mientras que, por su parte, los tribunales de los Estados miembros deben hacer lo propio a la vista de lo atribuido a los órganos de la entidad internacional. Se establecen de esta manera, de forma inevitable, acuerdos entre los dos órdenes judiciales. Y se produce así una verdadera interacción entre tribunales. La experiencia del Tribunal Europeo de Derechos Humanos, del Tribunal de Justicia de la Unión Europea, más también de la Corte Interamericana de Derechos Humanos, nos lo confirma.

Tratados, jurisprudencia y práxis ponen de manifiesto los instrumentos a través de los que la interacción se revela a fin de asegurar un satisfactorio nivel de compatibilidad entre los dos órdenes. Sobre todo, se conforma como norma general que los Estados y las respectivas jurisdicciones deban respetar lo convenido en los tratados; asimismo, la propia jurisprudencia de los tribunales internacionales. Esta suerte de vínculo de ajuste sucesivo es requerido por la jurisprudencia de los tribunales internacionales y asegurado por la estatal, imponiéndose, en los casos que resultare necesario, modificaciones legislativas, mas no sólo ello, también constitucionales, en orden a tal adecuación para garantizar los derechos humanos.

Cabe de esta forma la posibilidad de que el tribunal internacional llegue a solicitar al legislador estatal que adopte las medidas necesarias, compatibles con los tratados, para hacer desaparecer los motivos de fricción entre la jurisdicción nacional y aquella.

Así, por ejemplo, dentro de la jurisprudencia del Tribunal Europeo de Derechos Humanos, podemos citar la Sentencia de 22 de febrero de 2005, caso Hutten-Czapska v. Polonia, en materia de cánones de habitabilidad, donde el Tribunal solicitó al Estado polaco la aprobación de aquellas disposiciones normativas que permitieran en última instancia que no se produjera la vulneración de derechos individuales. También cabe apuntar las Sentencias de 28 de septiembre de 2000, caso Messina v. Italia, o de 10 de 
noviembre de 2004, caso Sejdovic v. Italia, sobre las comunicaciones de los reclusos y el juicio en rebeldía respectivamente.

Con relación a la Corte Interamericana de Derechos Humanos pueden citarse de igual forma diferentes resoluciones relativas, por ejemplo, a la imposición de la modificación de la legislación sobre la pena capital con el objeto de restringirla únicamente a los delitos más graves tal como dispone la Convención, como asesinatos (Sentencias de 21 de junio de 2002, caso Hilaire, Constantine y Benjamin y otros v. Trinidad y Tobago, y 20 de noviembre de 2007, caso Boyce y otros v. Barbados), desapariciones forzadas (Sentencia de 22 de noviembre de 2007, caso Gómez-Palomino v. Perú), interdicción de la tortura (Sentencia de 11 de marzo de 2005, caso Caesar v. Trinidad y Tobago).

La modificación solicitada puede ser de índole legislativa por tanto, pero no sólo ello, ya que cabe requerirse en algunas hipótesis, incluso, la necesidad de una reforma constitucional (Sentencias de 30 de mayo de 1999, caso Castillo Petruzzi v. Perú y de 5 de febrero de 2005, caso La última tentación de Cristo. Olmedo Bustos y otros v. Chile).

Son los tribunales estatales los que deben proporcionar una interpretación de su Derecho conforme a los tratados, esto es efectuar un control de convencionalidad que permita garantizar la conformidad de la normativa interna a los vínculos asumidos en los tratados. Por ejemplo, en Francia son los tribunales ordinarios y especiales quienes ejercen de forma difusa el control inaplicando aquellas leyes incompatibles con las convenciones suscritas conforme al artículo 55 de su texto constitucional que reconoce la supralegalidad de los tratados. Y en lo que respecta a los tratados en materia de derechos humanos surge la obligación de los jueces de aplicar la Convención también por medio de la intervención del juez de constitucionalidad.

El Consejo Constitucional, aun dejando a los jueces ordinarios el control de convencionalidad, reconoció en una muy relevante decisión que la jurisprudencia del Tribunal Europeo de Derechos Humanos se encuentra incardinada en el seno de la tradición constitucional francesa (Decisión 2004-505 DC).

En otros supuestos, como puede ser el italiano, cabe resaltar que el control venía siendo ejercitado de forma difusa por las diferentes instancias judiciales hasta que el Tribunal Constitucional se hizo garante directamente incorporando un control centralizado (Sentencias 348 y 349/2007).

En ocasiones se preve de forma expresa un reenvío judicial por parte del tribunal estatal al internacional con el objeto de asegurar la aplicación correcta de las disposiciones del Convenio.

Sin duda el supuesto más conocido es el contemplado en el seno de la Unión Europea con la denominada cuestión prejudicial que se convierte en un destacado instrumento de colaboración entre las instancias judiciales de los diferentes países de la Unión y el Tribunal de Justicia.

Aunque no debemos olvidar otros como el recogido en el Protocolo de Tegucigalpa de 1991 para la Corte Centroamericana de Justicia o el Protocolo de Cochabamba de 1996 para el Tribunal de Justicia de la Comunidad Andina. Tiene interés destacar que estos reenvíos han sido objeto de profusa utilización por parte de los tribunales de los países miembros de la Comunidad Andina en casos de propiedad intelectual.

La relación entre los dos órdenes de jueces se basan en general en un criterio de colaboración que pone de manifiesto una deferencia de carácter recíproco. Se intenta sal- 
vaguardar los propios principios fundamentales de referencia, así el Convenio y la Constitución, como muestra el supuesto del recurso a los denominados contralímites, progresivamente absorbido por su reflejo en los Tratados más recientes, en el caso de las relaciones entre el Tribunal de Justicia y los Tribunales Constitucionales estatales.

Mas también en el marco del Convenio Europeo de Derechos Humanos podemos encontrar provechosos ejemplos de colaboración como pone de manifiesto el reconocimiento por parte del Tribunal de Estrasburgo de la doctrina del márgen de apreciación nacional, como subraya la recíproca adecuación entre la jurisprudencia de éste y la del Tribunal Constitucional italiano respecto de la admisión de la intervención de terceros en el procedimiento por conflicto de competencias en materia de inmunidad parlamentaria (caso Córdoba y De Iorio) o la del Tribunal Constitucional polaco, supra citada, con relación a los canones de habitabilidad (caso Hutten Czapska).

Resulta igualmente significativa la relación entre la Corte Interamericana de Derechos Humanos con los tribunales estatales. Encontramos así un amplio número de supuestos de adaptación de las jurisprudencias de los diferentes Estados a lo previsto en la jurisprudencia de aquella — comprendiendo incluso modificaciones de los textos constituionales a consecuencia de lo decidido en sede convencional (caso Olmeda Bustos) eliminándose con efecto inmediato y erga omnes leyes de amnistía adoptadas en algunos ordenamientos al término de regímenes autoritarios.

\section{LA INFLUENCIA ENTRE JURISPRUDENCIAS ESTATALES.}

Si en las relaciones entre los tribunales convencionales y los estatales resulta posible extraer la vigencia de un principio fundamental de colaboración que implica una constante interacción que permitiría hablar propiamente de diálogo, no puede afirmarse lo mismo por el contrario en el caso de las relaciones entre tribunales estatales de nivel parejo. Aquí sólo puede constatarse la presencia de una influencia de la jurisprudencia de tribunales dotados de particular prestigio.

Una situación que evidentemente no ha surgido en los últimos tiempos, como consecuencia de la formación de un nuevo clima cultural tras la superación de encasillamientos ideológicos. En realidad existe desde mucho tiempo atrás por la inevitable y natural atracción que tienen determinados sistemas jurídicos, que tienen la fuerza de manifestarse como modelos merecedores no sólo de atención sino también de imitación. En estos casos estaríamos ante una influencia meramente unidireccional no apareciendo en modo alguno la interacción que es, en suma, la esencia del diálogo.

Entre el amplio abanico de supuestos disponibles podemos citar algunas destacadas resoluciones de la Corte Suprema de Justicia argentina en las que, ya desde las últimas décadas del siglo XIX, encontramos un recurso sistemático a la jurisprudencia del Tribunal Supremo norteamericano.

Citemos así, por ejemplo, una solicitud de hábeas corpus contra una orden de encarcelamiento dictada por la Cámara de Diputados, en donde puede observarse que la fundamentación de la Corte argentina se remite a la jurisprudencia del Tribunal Supremo norteamericano, y de forma más específica a la emblemática Marbury v. Madison (Sentencia de 22 de septiembre de 1887, caso Eduardo Sojo c. Cámara de Diputados de la 
Nación); o cuestiones atinentes a la no enjuiciabilidad de los actos políticos donde nuevamente se apuntan pronunciamientos previos de dicho Tribunal (Sentencia de 7 de septiembre de 1893, caso Joaquín M. Cullen c. Boldomero Llerena).

Mediante el recurso a precedentes judiciales de otro país la justicia argentina aclaró así, en épocas relativamente lejanas, dos cuestiones fundamentales de su ordenamiento constitucional que, por la ausencia de previsión constitucional en esos puntos, no hubiera podido solventar o colmar de otra forma.

En el caso de que estos episodios apuntados hubiesen acontecido en los últimos años probablemente habrían terminado siendo reconducidos al ámbito del diálogo entre tribunales; el hecho de que estos episodios escaparan en el pasado a las reflexiones doctrinales no los deviene de menor interés para el observador actual.

Analizado en sus justos términos puede constatarse, por tanto, que desde tiempo atrás no era en absoluto desconocido un fenómeno que, sin entrar en mayores profundidades, podrían considerarse influencias de la jurisprudencia de un tribunal estatal en otro. Pero influencia es distinto de interacción. Aquella es unidireccional; ésta implicaría una plausible reciprocidad.

De aquí una observación que nos parece obvia: sólo en los casos de interacción parece sensato recurrir al concepto de diálogo. Mas éste, en realidad, cubre únicamente una parte, aunque de gran relevancia, de las experiencias que podemos verificar. No parece a primera vista justificado el recurso al mismo para todos los supuestos en que se haga referencia a jurisprudencia de otros tribunales.

De esta forma, si bien es cierto que el desarrollo de las relaciones transnacionales ha supuesto un incremento notable de la difusión de las jurisprudencias, hay que destacar que el fenómeno de la influencia ejercida por un tribunal en otro no es en realidad un hecho nuevo motivado por ello. Y, en efecto, siempre han existido supuestos en los que un tribunal ha tomado como paradigma las sentencias de otros tribunales que le han servido de modelo.

Conforme nos acercamos en el tiempo podemos hacer reseña de otro supuesto: la relación entre la jurisprudencia del Tribunal Constitucional Federal alemán y el Tribunal Constitucional húngaro.

Tras la entrada en vigor de la reforma constitucional en Hungría de octubre de 1989, que, como es sabido, alteró la relación de competencias de este Alto Tribunal acercándolo al modelo habitual de los tribunales constitucionales europeos, aquél ha venido habiendo un uso sistemático de las previsiones constitucionales y la jurisprudencia del Tribunal Constitucional Federal alemán.

En numerosos ocasiones, a partir de la Sentencia 8/1990, el Tribunal se ha servido de la jurisprudencia sobre el artículo 1, parágrafo primero, de la Constitución alemana en orden a interpretar la cláusula contenida en el artículo 54 de su propia Constitución que establece el derecho a la dignidad humana.

Ha utilizado así la jurisprudencia externa para fundamentar el principio de la inviolabilidad de la dignidad humana configurándola como valor supremo y principio fundamental del resto de derechos, todo ello de manera pareja a lo previsto en el ordenamiento alemán.

Este principio fue utilizado de igual forma en una amplia batería de sentencias de gran calado. Aparte de las decisiones sobre el principio de dignidad, la práctica totalidad de las 
sentencias que fueron dictadas en la década de los noventa en materia de derechos fundamentales contenían referencias tanto explícitas como implícitas a la jurisprudencia alemana.

Pero esta es una relación claramente unidireccional, ya que las referencias de la jurisprudencia alemana a la húngara no se han producido en ningún supuesto. Por lo tanto, cabe hablar de monólogo del Tribunal hungaro mas no de diálogo; un monólogo fácilmente entendible por el intento de colmar un vacío en la experiencia en matería de garantías. Consecuencia, que duda cabe, de la herencia del período socialista, y que se unificó mediante la apelación a la riqueza del marco juridico, doctrinal y jurisprudencial alemán. Una tarea que se vio facilitada sobremanera por el hecho de que la mayoría de sus miembros tenían los conocimientos lingüisticos necesarios para realiza estas operaciones.

Resulta ciertamente indicativo este ejemplo: mientras que el Tribunal Constitucional de Hungría ha acudido de forma sistemática a la jurisprudencia del Tribunal Constitucional Federal alemán, éste no ha hecho lo propio al no precisar recurrir a otras fuentes jurisprudenciales para tratar de resolver sus casos.

No creemos que quepa hablar de este modo de diálogo sino de aproximaciones u homogeneidad en las orientaciones jurisprudenciales en cuestiones comunes como podrían ser la protección del medio ambiente o cuestiones de corte sensible como los símbolos religiosos, el aborto, la eutanasia, el matrimonio homosexual u otras similares.

Absolutamente peculiar es el caso de Sudáfrica, donde la ausencia de una tradición propia llevó a prever de forma específica en su texto constitucional el recurso a la apertura externa. El Tribunal Constitucional recurre así de forma habitual a resoluciones de otros tribunales; una actuación rara vez correspondida.

Ejemplos interesantes de interacción los vemos en ordenamientos basados en el common law del mundo jurídico anglosajón. Estados soberanos que dejaron atrás su inicial configuración como Dominions; entre los más relevantes cabe citar Australia, Canadá, Nueva Zelanda o India. Se mantiene aquí una cierta política de continuidad e interdependencia con la jurisprudencia británica y un diálogo particularmente intenso.

Pero incluso en estos casos este diálogo puede resultar problemático.

Con cierto detalle ha sido estudiado el caso canadiense y la acogida por parte de sus tribunales de la jurisprudencia de los Estados Unidos. La cercanía geográfica y cultural ha derivado en la observación del ordenamiento vecino y de forma más singular desde el momento de la aprobación de su Carta de Derechos. Mas no debe olvidarse que ya desde mediados del siglo XIX los tribunales de este país venían recurriendo de forma amplia a los precedentes de los tribunales de Estados Unidos. Una apertura ciertamente significativa que no ha tenido correspondencia; han sido escasos los supuestos en que los tribunales norteamericanos han apelado a precedentes canadienses como así lo han mostrado los diferentes estudios realizados sobre las relaciones entre los tribunales de ambos países.

Como ejemplo de esa apertura de la jurisprudencia canadiense podríamos citar el asunto resuelto en Keenstra (The Queen v. Keenstra, 3 S.C.R. 697 -1990_) en un supuesto de discurso de odio. En un caso similar conocido poco tiempo después, apenas dos años, por el Tribunal Supremo norteamericano (R.A.V. vs City of St. Paul, Minnesota, 505 US 377 - 1992 - ) podemos observar que este optó por no tomar en cuenta el precedente de su homólogo canadiense. No existiría por tanto interacción recíproca entre ambos tribunales. La receptividad sería así meramente unilateral del tribunal canadiense; un discurso en sentido único. 
Resulta arduo, en conclusión, identificar supuestos de influencia recíproca entre jurisprudencias. De principio no se producen intercambios de experiencias mediante el encuentro de las mismas sino que nos encontraríamos únicamente ante un mero recurso unilateral de un tribunal a la jurisprudencia del otro. De otro lado, es cuantitativamente escasa, — si hacemos una valoración global del trabajo de los tribunales en su conjunto-, la manifestación explícita por parte de un tribunal de la jurisprudencia externa en sus razonamientos.

Poner en cautela un recurso acrítico y estéril —en términos científicos- del concepto de diálogo, una vez comprobado empíricamente la ausencia de reciprocidad emulativa entre jurisprudencias, no debe llevar a excluir que la disposición abierta de un tribunal a la jurisprudencia de otros merezca consideración al valorar los diversos métodos interpretativos que se pueden encontrar en la práctica de los tribunales.

Existen sin duda numerosos ejemplos de jueces sensibles a los precedentes de otros tribunales que al exponer sus razonamientos confrontan, cuestionándose, experiencias externas (no sólo precedentes judiciales pertinentes en realidad sino también disposiciones constitucionales o legislativas e incluso construcciones doctrinales extranjeras). En estos casos el juez abre un proceso de diálogo crítico en el curso de su proceso argumentativo, dentro del cual confronta los parámetros que ofrece el propio Derecho y sus precedentes cotejándolo críticamente con otros Derechos y precedentes; un recurso que se efectúa no tanto para resolver el caso en sí como para valorar mejor el Derecho interno de cara a su solución.

\section{LA NEGATIVA Y LA IMPOSIBILIDAD MÁS O MENOS RADICAL DE DIÁLOGO.}

En marcado contraste con el mito del diálogo son los casos en que este es rotundamente rechazado.

Así, en algunos países que han desarrollado con cierta rapidez el régimen de derechos propio de de las tradiciones constitucionales liberales, siendo constreñidos a recibir el Convenio Europeo de Derechos Humanos, el rechazo del diálogo puede devenir traumático.

Cabe citar por ejemplo el caso de las relaciones entre el Tribunal Constitucional de Bosnia y Herzegovina y el Tribunal Constitucional de la República Serbia de Bosnia. El tribunal estatal había declarado inconstitucionales mediante Sentencia de 30 de marzo de 2006, las normativas, en materia de símbolos identitarios, de la República Serbia de Bosnia y de la Federación croata-musulmana, las dos entidades constitutivas del Estado. Y ello reconociendo incluso la legitimidad del derecho a preservar las tradiciones y culturas locales. El fallo no se acató a nivel legislativo por ninguna de las dos entidades interviniendo nuevamente el tribunal declarando, a través de la Sentencia de 27 de enero de 2007, la nulidad de las disposiciones recurridas. Fue tras este fallo cuando se produjo el rechazo explícito de la colaboración. El Tribunal serbo-bosnio procedió a declarar «irrelevante» el pronunciamiento del primero (Sentencia de 18 de junio de 2007).

En términos más generales, con relación a tribunales estatales, encontramos ejemplos en donde se pone de manifiesto la ausencia de interés sobre experiencias foráneas o cualquier tipo de contacto colaborativo. En pocas palabras, se plantean obstáculos a 
aceptar el producto de la actuación de tribunales que con base en normativas convencionales y constitucionales, podrían utilizarse en sus pronunciamientos.

En la práctica, en la mayoría de los casos prima el criterio de discrecionalidad de los tribunales a la hora de la apertura al exterior. Plena autonomía valorativa por tanto.

El caso más notorio en los que la autonomía conduce a una cerrazón al diálogo es el que nos ofrece la línea aislacionalista seguida por el Tribunal Supremo de los Estados Unidos, cuestión sobre la que, en los últimos años, se ha terminado por producir un interesante debate que no parece próximo a concluir. Existe una suerte de freno a la propia legitimidad de acudir a contribuciones de la jurisprudencia de otros países. Pero no se queda ahí ya que en sus manifestaciones de mayor fuerza discuten igualmente la efectividad de la validez jurídica del Derecho internacional de los tratados; en rigor, aplicable y eficaz en el ordenamiento estadounidense. En ocasiones, no obstante, incluso en un clima de rechazo de las consideraciones de otras experiencias jurisprudenciales puede acontecer que el precedente extranjero se considere de utilidad.

Un caso ciertamente singular es el que se manifiesta en el voto particular del magistrado Scalia en el caso Lawrence v. Texas. Este magistrado, paladín de la autosuficiencia del ordenamiento norteamericano, en el pensamiento de que la despenalización de las conductas homosexuales pudiera abrir la puerta al reconocimiento judicial del matrimonio entre personas del mismo sexo, recurrió aquí al argumento comparatista en negativo, citando la jurisprudencia canadiense: «El Tribunal pretende hoy... que no debemos tener miedo al mandato judicial sobre los matrimonios homosexuales como recientemente ha ocurrido en Canadá»

Existe también supuestos de rechazo de utilización de materiales jurídicos procedentes de jurisdicciones externas vinculados a los criterios de selección que algunos tribunales utilizan.

En efecto, en casos como el de Sudáfrica donde el Tribunal Constitucional viene utilizando sistemáticamente elementos jurídicos de otros ordenamientos, motivado por la previsión contemplada expresamente en el artículo 39 de su Constitución vigente de 1996, encontramos también episodios en los que se rechaza de forma expresa la utilización de precedentes extranjeros; así, a título de ejemplo, puede verse la Sentencia Mashavba v. Presidente de la República de Sudáfrica y otros, 2004 (3) BCLR 292 (T)—.

El rechazo al diálogo no se produce sólo aquí sino también en el curso de la relación entre tribunales constitucionales o supremos con relación a la jurisprudencia de tribunales internacionales.

Así, la Corte de Casación italiana, que ha sido ejecutor fiel en líneas generales de las resoluciones del Tribunal de Estrasburgo, ha rechazado en ocasiones una observación completa de aquellas, como aconteció con el punto relativo al cálculo del tiempo con el que valorar el plazo razonable de la duración del proceso recogido en el artículo 6 del Convenio Europeo de Derechos Humanos

O la Cámara de los Lores, que manifestó su disconformidad, en el ámbito de este mismo artículo, al negar la pretendida violación en supuestos en los que se había pronunciado un tribunal militar británico.

También, el Tribunal Constitucional Federal alemán, que en la sentencia Gürgülu dio preferencia al respeto de los propios principios constitucionales dejando de lado los principios del Convenio. 
Y siempre, en el seno de esta óptica de cautela hacia una apertura indiscriminada al exterior, debe recordarse lo acontecido con los denominados contralímites: algunos tribunales constitucionales como una suerte de medida de prudencia avanzaron el linde de los principios constitucionales irrenunciables en la eventual confrontación con la jurisprudencia del Tribunal de Justicia. La conocida sentencia del Tribunal Constitucional Federal Alemán de junio de 2009 reitera esta reserva.

En la actualidad las eventuales objecciones a la operatividad del Derecho y la jurisprudencia internacional sobre derechos humanos en ocasiones vienen provocados por el objetivo de preservarse frente a orientaciones jurisprudenciales de los tribunales internacionales o supranacionales que pueden entenderse excesivamente progresistas para ser recibidas por la sensibilidad social mayoritaria en la comunidad estatal y no tanto, en consecuencia, por el de proteger los principios fundamentales de los derechos previstos constitucionalmente.

En esta línea se ha destacado que la jurisprudencia que admite la posibilidad de adopción por parte de homosexuales o que reconoce efectos jurídicos a las uniones entre personas del mismo sexo (Sentencia del Tribunal de Justicia de las Comunidades Europeas de 1 de abril de 2008, Tadao Maruko v. Versorgungsanstalt der deutschen Bubnen y Sentencia del Tribunal Europeo de Derechos Humanos de 22 de enero de 2008. EB v. Francia) se contrapondría a las tradicionales orientaciones de muchos Estados miembros.

Lo mismo puede señalarse con relación al supuesto del fallo del Tribunal de Estrasburgo de 2 de noviembre de 2009 que declaró contrario al Convenio la exposición del crucifijo en los colegios.

\section{LA COMPARACIÓN COMO COMPONENTE DEL SUPUESTO DIÁLOGO.}

Tras haber constatado que no resulta posible hablar de una extensión generalizada del diálogo, nos queda por afrontar un segundo mito presente en buena parte de la doctrina que se ocupa del papel de los tribunales: la generalización del recurso a la comparación. Y al hilo de esto resulta necesario distinguir entre la apertura cierta de los tribunales al derecho extranjero y el recurso a la comparación. Parece evidente que ambas actitudes no coinciden necesariamente. También debe distinguirse entre el simple interés o la vocación y actitud ante la comparación, constatada en ocasiones en la fórmula de utilización del argumento comparativo, de la comparación real llevada a cabo por un tribunal.

La posibilidad de que un tribunal recurra al derecho extranjero es seguramente una facultad que no cabe excluir cuando se entiende que resulta de utilidad de cara a la resolución del caso. De esta manera no se trata de un recurso a una fuente externa como si lo sería en el caso de reenvío a través de una previsión normativa ad hoc, sino que simplemente se considera como un dato fáctico el Derecho externo, tal y como sería si se citara un hecho histórico o una interpretación doctrinal.

Las referencias al Derecho de otros ordenamientos resultan frecuentes tanto en la jurisprudencia de los tribunales estatales como en la de los internacionales, y en este caso, la reseña puede ser no sólo a los precedentes de tribunales de los Estados miembros sino también a la de otros Estados. 
No nos faltan ejemplos en los que los tribunales han podido considerar útil o necesario recurrir al Derecho extranjero.

Podemos citar así el conocido caso Englaro (Sentencia de la Corte de Casación italiana de 16 de octubre de 2007) donde la reseña al Convenio de Oviedo así como a algunas sentencias de tribunales alemanes, ingleses o norteamericanos o a la jurisprudencia del Tribunal Europeo de Derechos Humanos, resultan pasajes esenciales en la argumentación de la Corte. La comparación sirvió aquí para colmar un vacío normativo en el ordenamiento italiano que nada disponía sobre el fin de la vida.

O, volviendo a la jurisprudencia del Tribunal Constitucional de Sudáfrica, los casos Du Plessis y otros v. De Klerck y otros —1996 (3) SA 850 (CC)_ y The State vs. Makwanaye — 1995 (3) SA 391 (CC)_ donde se incorporan como elementos fundamentales de su ratio decidendi precedentes alemanes, australianos, ingleses, neozelandeses y norteamericanos o del propio Tribunal Europeo de Derechos Humanos al abordar los derechos fundamentales y las relaciones entre particulares y la pena de muerte, respectivamente.

De manera similar se han revelado esenciales las citas del Tribunal Supremo canadiense a los precedentes de su homónimo norteamericano así como al Tribunal Europeo de Derechos Humanos en materia de derecho negativo de asociación (R. v. Advance Cutting and Coring Lmt (2001) 3 SCR 209, 2001 SCC 70).

Lo cierto es que resulta extremadamente variada la posición o actitud de los tribunales frente al Derecho externo y la comparación.

Encontramos un amplio abanico que va desde aquellos tribunales que no manifiestan interés de utilizar fuentes externas, como podría ser el ya referido ejemplo del Tribunal Supremo de Estados Unidos, a otros que, en diferente medida, muestran su apertura a las mismas.

Cabe citar así la postura del Consejo Constitucional francés, que en sus decisiones se muestra permeable a los precedentes de otros tribunales, de forma particular los de los tribunales alemán o español, aunque únicamente de forma indirecta y sin hacer reseña expresa a fuentes externas.

Otros tribunales, por el contrario, abundan en citas de Derecho extranjero o sentencias de tribunales extranjeros. En buena medida se trata de una forma de erudición discursiva, de la reconstrucción de un horizonte de reconocimiento que permite ofrecer una panorámica sobre el Derecho próximo al caso pendiente de resolución; de citas que tratan de reforzar la argumentación del tribunal, una suerte de comprobación probatoria.

Tales llamadas suponen cierto reconocimiento de normas o precedentes judiciales vinculados en alguna forma con el caso a resolver. A lo sumo, podemos considerar si el recurso al Derecho externo incide en la conformación del criterio del tribunal aunque, repitamos, no debe llevarse a error al hablar de comparación, en tanto que no existe certeza de que tal recurso entre en la ratio decidendi.

Encontramos de igual forma supuestos en los que los jueces proceden en sentido propio a la comparación entre diversas contribuciones jurisprudenciales e igualmente entre diferentes disposiciones constitucionales.

Lo acontecido con las experiencias de países como Canadá, Australia o Sudáfrica nos pone de manifiesto la utilización de previsiones contenidas en textos constitucionales o convenios, principios jurídicos generales, sentencias de tribunales internacionales, acervo doctrinal, etc. 
No se trata por tanto únicamente del recurso a la comparación de precedentes jurisprudenciales. Esta confrontación reconstructiva de un principio jurídico, por ejemplo en temas como la pena de muerte o los tratamientos inhumanos y degradantes, utilizando fuentes ciertamente diversificadas, permite la contrucción del parámetro a utilizar para declarar la constitucionalidad o inconstitucionalidad de de la ley sometida al juicio del Tribunal.

La disposición contenida en la Constitución provisional de Sudáfrica (1993-1996), precedente de la actualmente vigente, que habilitaba a los tribunales a utilizar el Derecho extranjero podía calificarse sin duda de singular.

Recordemos que recogía en el apartado primero de su artículo 35 una habilitación expresa al recurso a la comparación; de esta forma, en la interpretación de su Carta de Derechos los tribunales podrían tener en cuenta, caso de resultar aplicable, el Derecho internacional público referido a los derechos así como la jurisprudencia extranjera. Se contemplaba así de forma expresa la posibilidad del recurso a esta subordinándolo a su compatibilidad.

La Constitución finalmente aprobada, en la actualidad vigente, se limitó a contemplar en su artículo 39 el recurso al Derecho extranjero, aunque resulta innegable que el Tribunal sudafricano continúa actuando como si la primera formulación, supra apuntada, todavía estuviera en vigor.

La previsión explícita de ese recurso al Derecho extranjero y a la comparación es un dato de enorme interés y muestra que la relevancia de otros ordenamientos ha influido igualmente en el constituyente.

\section{LA CONFUSIÓN ENTRE ARGUMENTOS COMPARATIVOS Y JUICIOS COMPARATIVOS.}

Existe una disparidad notable entre el recurso a precedentes de otros tribunales y el recurso a la comparación.

Buena parte de las reflexiones que podemos ver sobre el uso de la comparación tanto por parte de los tribunales constitucionales como internacionales abordan en realidad casos en los que los tribunales toman en consideración el Derecho o jurisprudencia de ordenamientos externos; supuestos que probablemente puedan resultar numerosos.

Mas es constatable una diferencia evidente entre argumento comparativo y juicio comparativo.

A nuestro criterio, únicamente resulta apropiado hablar de comparación cuando el proceso de interpretación y resolución consiente concretar el razonamiento comparativo de forma intrínseca a la ratio decidendi.

Del examen crítico de las aportaciones de los diferentes ordenamientos respecto de las decisiones debería conformarse la regla a utilizar en el caso concreto en orden a su rsolución.

El juzgador debería para ello encontrarse ante una situación de carencia de su ordenamiento de referencia, cuestión que habitualmente ello no sucede, al ser posible posible la utilización del propio sistema de fuentes y precedentes jurisprudenciales respecto a los que el recurso a la aportación foránea termina teniendo un mero valor auxiliar, por más que en ocasiones pudiera llegar a resultar significativo o, más aún, esencial. 
La adecuada comprensión del alcance del eventual recurso al Derecho extranjero, que actuaría como elemento cognitivo clarificador y no como fuente directamente aplicable derivado de un reenvío, nos exige hacer una reseña cuando menos esquemática de la experiencia de diferentes ordenamientos que habitualmente, aunque con fórmulas diversas, vienen utilizando, según se señala, el método comparativo, el elemento comparativo, o la comparación.

Tenemos de hecho una amplia panoplia de supuestos adscribibles a ese recurso ornamental al Derecho externo, en los casos en que el tribunal reseña en su pronunciamiento otros Derechos y jurisprudencias, y de casos en que la cita se entiende útil de cara a reforzar la argumentación.

El elemento comparativo de ese último caso pretende servir de argumento de autoridad; cita de fuente o autoridad de prestigio reconocida y fiable. Un uso que se deja al arbitrio del juzgador.

Un punto habitualmente no abordado es el hecho de que el recurso al Derecho externo no resulta, o al menos no de forma determinante, traducible en la resolución final. También resulta complejo cotejar la magnitud del aporte cognoscitivo de las fuentes externas en las diferentes fases del proceso, ya en la instructoria o durante los oportunos debates. Probablemente los abogados en sus argumentaciones se apoyen en elementos externos como también lo hará el ministerio público. Así lo ponen de manifiesto las conclusiones de los Abogados Generales ante el Tribunal de Justicia de la Unión.

La relación de las citas es amplia y puede ir de textos constitucionales o tratados internacionales a reseñas legislativas, jurisprudenciales — tanto de tribunales estatales como internacionales - o incluso comentarios doctrinales.

Podemos tomar como ejemplo al Tribunal Supremo de Canadá.

En el caso R. v. Advance Cutting E Coring Ltd (2001) 3 SCR 209, 2001 SCC 70 hubo de decidir si el derecho de asociación contenido en la sección 2 (d) de la Carta de Derechos y Libertades incluía o no el derecho de no asociación. Tanto en el fallo como en los votos particulares se pusieron de manifiesto elementos externos al propio ordenamiento y en particular referencias detalladas a la Constitución de los Estados Unidos, a la jurisprudencia de su Corte Suprema y asimismo a la del Tribunal Europeo de Derechos Humanos; con reseñas incluso a la doctrina jurídica europea. Ejemplos de un uso promiscuo de los elementos a tener en cuenta no faltan. Numerosas y variadas son las reseñas a constituciones, legislaciones, jurisprudencias o doctrina en la jurisprudencia de Sudáfrica.

Por su parte, en Lawyers for Human Rights y Anna Francis Eveleth v. Minister of Home Affairs, 2003 (8) BCLR, 891 (T), al tratar de interpretar la sección 38 del texto constitucional en materia de legitimación, en el supuesto de lesión de un derecho constitucionalmente garantizado, el Tribunal citará jurisprudencia canadiense e india.

En State v. Russel Mamabolo y otros, CCT 44/00, caso atinente al desacato judicial, el Tribunal invocará, con relación a la sección 16 de la Constitución, normas constitucionales de un amplio número de países, examinando asimismo su jurisprudencia, no solo constitucional (Australia, Canadá, Estados Unidos, Gran Bretaña, Hong Kong, India, Namibia, Nueva Zelanda y Zimbawe).

No nos cabe duda que el enriquecimiento que supone la apelación a un conjunto diverso de fuentes puede traducirse en el pronunciamiento final y que para poder hablar propiamente de recurso a la comparación no resulta suficiente una mera acumulación de 
citas. Habría que comprobar aquí el alcance de tal influencia. Una doctrina de la comparación judicial sólo puede encontrar sustento en el cotejo de las líneas de argumentación concretado en la sentencia y no en simples reconstrucciones en buena parte forzadamente inductivas.

Entendida en sentido propio la comparación, así, inserta en el razonamiento que apuntala el fallo, determina que el tribunal debe proceder a explicar las razones de acudir a tales recursos. En otras palabras parece correcto hablar de comparación en aquellos casos en que esta sea deducible de forma explícita del texto de la sentencia.

Esto nos lleva a tomar con mucha cautela la afirmación de un supuesto recurso a la comparación todas las veces en que en la sentencia de un tribunal constitucional, como el italiano, recoge pasajes en los que se citan legislaciones o jurisprudencias extranjeras. Todos los ejemplos en los que la cita tiene un carácter meramente confirmativo o de refuerzo de la decisión que el tribunal asume.

Lo cierto es que resulta poco habitual pasar de un mero recurso meramente ornamental de las citas o de un simple intento de querer dar una mayor consistencia y persuasión con las mismas, a un escalón superior de reflexión que ponga de manifiesto o demuestre como el tribunal ha basado su fallo en Derecho foráneo y su estudio comparativo.

Un ejemplo de esto último nos lo ofrece, como ya hemos apuntado, la jurisprudencia del Tribunal Constitucional de Sudáfrica que ha utilizado sistemáticamente el impulso ofrecido por la disposición constitucional que de forma expresa habilita la utilización de los derechos extranjeros e internacional.

En el caso The State v. Makwanyane el tema abordado era la constitucionalidad o inconstitucionalidad de la pena de muerte: ¿resultaba acaso compatible con su nueva Carta de Derechos? Recordemos que la Constitución preveía explíticamente el derecho a la vida, el derecho a la dignidad, el derecho a no ser sometido a penas crueles e inhumanas. Todos ellos derechos limitables, mas dentro siempre de los límites admisibles en una sociedad abierta y democrática basada en la libertad y la igualdad. Pero nada preveía de forma expresa sobre la pena de muerte. El Tribunal volvió en este caso la mirada al Derecho y precedentes externos enfrentándose a un volumen amplísimo de tratados, constituciones, sentencias, interpretaciones doctrinales y estadísticas de todos los lugares del mundo. Particularmente extensa fue la jurisprudencia consultada en los tribunales norteamericanos. El material estudiado permitía colmar el vacío de la regulación estatal aportando elementos a favor o en contra de la constitucionalidad de dicha pena. En última instancia, tras esa confrontación crítica, el Tribunal terminó considerando que la pena capital no era en modo alguno compatible con el reconocimiento de la dignidad de la persona, aportando sobre la base de ese estudio comparatista el principio de Derecho necesario para la resolución del caso.

El recurso a la comparación en la jurisprudencia de los tribunales internacionales tiene lógicamente características propias. Si bien resulta habitual afirmar que se sirven de la comparación como instrumento, lo cierto es que en la práctica se mueven con absoluta discreccionalidad utilizando el Derecho de los Estados miembros que consideren más adecuado en orden a resolver los casos concretos En la jurisprudencia del Tribunal Europeo de Derechos Humanos o del Tribunal de Justicia de la Unión Europea no se produce, por ejemplo, como a primera vista podría considerarse, una sistemática comparación entre la diversa legislación y jurisprudencia de los Estados miembros. También en relación con estos tribunales sucede que profundizan en el conocimiento de las solucio- 
nes normativas o jurisprudenciales previstas en el ordenamiento de los Estados miembros en la fase instructoria y en ocasiones en los posteriores debates.

Resulta pacífico por tanto la posibilidad de ese proceso cognoscitivo en el que el juzgador profundiza en el conocimiento del Derecho estatal relevante y puede proceder a una evaluación comparativa de las diversas fuentes disponibles. Mas, como regla, no suelen encontrarse sino reseñas indirectas en el texto de las sentencias de las que no cabe deducir un sistemático recurso al Derecho de los Estados miembros.

El recurso al método comparativo, del que se habla frecuentemente, viene a significar sencillamente el recurso a los materiales que pueden ofrecer el ordenamiento o los ordenamientos que pueden considerarse de utilidad para resolver el caso concreto como apunta, a título de ejemplo, la Sentencia Dorsch del Tribunal de Justicia de la Unión en materias de responsabilidad por actos legislativos, donde se utilizaron institutos propios del Derecho alemán, belga y francés, mas no del resto de ordenamientos (Sentencia de 28 de abril de 1998, Dorsch Consult v. Consejo y Comisión - T-184/95- y Sentencia de de 15 de junio de 2000 Dorsch Consult v. Consejo y Comisión -C-237/98-.

Diferente modo de actuar que en el caso Algera; un asunto donde el Tribunal por primera vez se pronunció incluyendo la comparación en el seno de la propia ratio decidendi: ante la ausencia en el Tratado de disposiciones específicas en el tema objeto de controversia, el Tribunal estudió las regulaciones previstas en la legislación, las interpretaciones doctrinales y la jurisprudencia de los Estados miembros y tras el reconocimiento comparado de sus tradiciones jurídicas —en aquel momento eran seis los componentes de las Comunidades - acordó el "principio de revocabilidad de las medidas ilegítimas al menos dentro de un plazo razonable de tiempo» (asuntos acumulados C7/56, C-3 / 57, C-7/57, Dineke Algera y otros v. Asamblea Común, Sentencia de 12 de julio de 1957, par. 56). En este caso el juez deduce de la comparación de los diferentes ordenamientos estatales el principio con el que resolver el caso concreto.

Debemos terminar estas notas reseñando que tanto en la práctica estatal como en la internacional resultan extraños los supuestos en los que el recurso a la comparación se pone de manifiesto de forma explícita en la fase decisoria permitiendo una verificación científicamente válida del recorrido argumentativo seguido por el Tribunal.

$$
* * *
$$

TITLE: Dialogue among Courts.

ABSTRACT: The paper deal the so-called dialogue between courts and specially if that term, dialogue, is the most appropriate to refer the wide range of issues that the doctrine blanket in it. The author analyzes too the existence of different perspectives of dialogue.

RESUMEN: El trabajo aborda el denominado dialogo entre tribunales reflexionándose sobre si la utilización de ese término, diálogo, es o no el más apropiado para referirse a la amplia variedad de cuestiones que la doctrina cobija en su seno. Se analiza igualmente la existencia de una amplia diversidad de perspectivas del diálogo en función de si se produce en el seno de las relaciones entre tribunales de un ordenamiento internacional regional y los tribunales estatales en ella insertos o bien entre tribunales estatales.

KeY Words: Dialogue. Courts.Law. Case Law.

Palabras Clave: Diálogo. Tribunales. Derecho. Jurisprudencia.

FeCHA DE RECEPCión: 25.06.2011. FeCha DE ACEPTACión: 29.06.2011. 
